\title{
Properties of Carbon Black/SBR Rubber Composites Filled by Surface Modified Carbon Blacks
}

\author{
Shuang-Ye Dai ${ }^{1}$, Ge-You Ao ${ }^{2}$ and Myung-Soo Kim ${ }^{1,2, \uparrow}$ \\ ${ }^{1}$ Department of Nano Science and Engineering, Myongji University, Yongin, Gyonggi-do 449-728, Korea \\ ${ }^{2}$ Department of Chemical Engineering, Myongji University, Yongin, Gyonggi-do 449-728, Korea \\ ‘e-mail: myungkim@mju.ac.kr \\ (Received May 14, 2007; Accepted June 15, 2007)
}

\begin{abstract}
Properties of carbon blacks and carbon black/SBR rubber composites filled by surface modified carbon blacks were examined. Although the specific surface area of carbon blacks increased after the surface modifications with heat, acid, and base, there were no obvious changes in resistivity. The composites filled by heat treated carbon blacks showed a higher tensile strength and elongation than those filled by raw blacks. The acid and base treated carbon blacks filled composites also showed higher tensile strength but similar elongation values with those filled by raw blacks. With increasing loading ratio, both tensile strength and elongation increased, and appeared a maximum value at 30-40 phr. Modulus at $300 \%$ strain remained increasing with further loading of carbon blacks. At the same loading, the heat treated black filled composites showed similar modulus values with composites filled by raw blacks but for base and acid treated black filled composites much higher values were obtained. After the surface modification, the functional groups which played an important role in reinforcement action were changed.
\end{abstract}

Keywords : Carbon black, Surface modification, Rubber reinforcement, Mechanical properties

\section{Introduction}

Most usage of elastomers would be impossible without the reinforcing character of certain fillers, such as carbon blacks [1]. However, carbon blacks without any treatments can not be used directly for commercial applications. Certain kinds of surface modifications are necessary, and various methods have been used to modify the surface characteristics of carbon blacks [2-5]. By appropriate surface treatment, the physical properties can be easily changed. Generally, the surface modification of different materials gives rise to surface energy that plays an important role in the adhesion of filler and polymer [6].

Discovered in the early $20^{\text {th }}$ century, the reinforcing action of carbon blacks in rubber has been studied in depth in numerous investigations, but the phenomenon has not been fully understood by now. It is generally accepted that this phenomenon is, to a large extent, dependent on the physical interactions between the filler and rubber matrix, which can determine the degree of adhesion at interactions. Van der Waals forces are supposed to give rise to reinforcing effects, whereas for superior reinforcing action, the adhesion between filler and polymer, chemical interaction and physical entrapment of free molecules are desirable. In simply appoint, the term of reinforcement relates to the changes in the mechanical properties, such as an increase in modulus, elongation at break, and tensile strength [7-10].

In this work, the different surface treatments of heat, acid, and base were conducted to find out proper surface modification method for carbon blacks improving mechanical properties of carbon black/rubber composites and to investigate the role of surface chemistry of modified carbon blacks on the rubber reinforcement action.

\section{Experimental}

\subsection{Materials and Sample preparation}

Carbon blacks N330 fluffy (N330-f) were supplied by DC Chemical. Co., Ltd. Styrene butadiene rubber (SBR-1502) was provided by Kumho Petrochemical Co., Korea. Carbon blacks denoted by N330-f-H, N330-f-B and N330-f-A were raw N330-f black treated by heat, $\mathrm{KOH}$ and $\mathrm{H}_{3} \mathrm{PO}_{4}$, respectively.

Heat treatment was conducted in a fixed bed furnace (Super Kanthal Tube Furnace) at $1300^{\circ} \mathrm{C}$ for $2 \mathrm{~h}$ in a nitrogen atmosphere. Chemical treatments were processed with $0.1 \mathrm{~N} \mathrm{KOH}$ and $0.1 \mathrm{~N} \mathrm{H}_{3} \mathrm{PO}_{4}$. Raw carbon blacks were stirred in the chemical solution for $24 \mathrm{~h}$, after that the residual chemicals were removed by boiling carbon blacks with acetone at about $62^{\circ} \mathrm{C}$ for $2 \mathrm{~h}$, and finally, carbon 
Table 1. Compounding formulations of SBR rubber composites

\begin{tabular}{cc}
\hline Ingredients & Loading [phr] \\
\hline Rubber $^{\mathrm{a}}$ & 100 \\
Carbon blacks $^{\mathrm{b}}$ & $0 \sim 60$ \\
Zinc oxide & 5 \\
Stearic acid $^{\mathrm{d}}$ & 2 \\
Dispersive agent $^{\mathrm{c}}$ & 3 \\
Accelerator $^{\mathrm{d}}$ & 1 \\
Sulfur & 2 \\
\hline
\end{tabular}

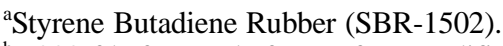

${ }^{\mathrm{b}} \mathrm{N} 330-\mathrm{f}$ before and after surface modification.

cEF44.

${ }^{\mathrm{d}} \mathrm{N}-$ Oxydiethylene-2-benzothiazolesulfenamide.

blacks were washed by distilled water for several times and dried in a vacuum oven at $100^{\circ} \mathrm{C}$ for $24 \mathrm{~h}$. Before mixing with the rubber, chemically modified carbon blacks were well ground.

Table 1 shows the compounding formulations in this experiment. The mixing process was carried out in a Haake Rheomix 600 mixing head. The filling level of the mixer chamber was $70 \%$, and the total mixing time and rotator speed were $26 \mathrm{~min}$ and $45 \mathrm{rpm}$, respectively. Before measuring the mechanical properties of composites, the filled SBR rubbers were cured for 35 min under $1 \mathrm{MPa}$ at $145^{\circ} \mathrm{C}$ under a CARVER hot press according to ASTM D 3185.

\subsection{Measurements of surface and mechanical properties of carbon blacks and composites}

The BET surface area and pore size distribution of carbon blacks were characterized by physical adsorption tests with $\mathrm{N}_{2}$ as the adsorbate at $77 \mathrm{~K}$ with a surface analyzer (Automatic Volumetic Sorption Analyser, Autosorb-1, Quantachrome). Resistivity of carbon blacks was tested by a digital multi-meter (Hioki Co., HI Tester 3540) after the carbon black samples being kept under a constant pressure 1,000 psi for about $20 \mathrm{~min}$ by a power press (ISE-WP 10T, Enerpac, USA). The microstructure and surface of carbon black and rubber cross fraction were observed by Scanning Electron Microscope (SEM). The tensile strength of composites was determined by a UTM machine (LLOYD LR5K) at room temperature with a crosshead speed of $500 \mathrm{~mm} / \mathrm{min}$ under room temperature according to ASTM standards. The surface chemistry of carbon blacks before and after surface modification was tested by a Fourier Transform-Infrared Spectrophotometer machine (FT-IR, BOMEM 104).

\section{Results and Discussion}

\subsection{Properties of carbon blacks before and after surface modification}

Properties of carbon blacks before and after surface modification are presented in Table 2 . It could be seen that the surface modified carbon blacks showed a higher specific surface area than raw blacks. But there were no significant changes in resistivity. Among them, the N330-f-H black showed the highest specific surface area accompanied with the highest total pore volume, which might be caused by removing unstable functional groups or less ordered carbon species and forming pores in carbon black aggregates after

Table 2. Properties of carbon blacks before and after surface modification

\begin{tabular}{|c|c|c|c|c|c|}
\hline Sample & $\begin{array}{l}\text { Resitivity } \\
(\Omega \cdot \mathrm{cm})\end{array}$ & $\begin{array}{l}\text { Meso pore volume } \\
\left(\mathrm{cc} \cdot \mathrm{g}^{-1}\right)\end{array}$ & $\begin{array}{l}\text { Micro pore volume } \\
\qquad\left(\mathrm{cc} \cdot \mathrm{g}^{-1}\right)\end{array}$ & $\begin{array}{l}\text { Total pore volume } \\
\qquad\left(\mathrm{cc} \cdot \mathrm{g}^{-1}\right)\end{array}$ & $\begin{array}{c}\text { BET } \\
\left(\mathrm{m}^{2} \cdot \mathrm{g}^{-1}\right)\end{array}$ \\
\hline Raw N330-f & 0.0744 & 0.10406 & 0.03667 & 0.14073 & 74 \\
\hline N330-f-B & 0.0602 & 0.09204 & 0.04764 & 0.13968 & 80 \\
\hline N330-f-A & 0.0711 & 0.11600 & 0.04923 & 0.16523 & 90 \\
\hline
\end{tabular}

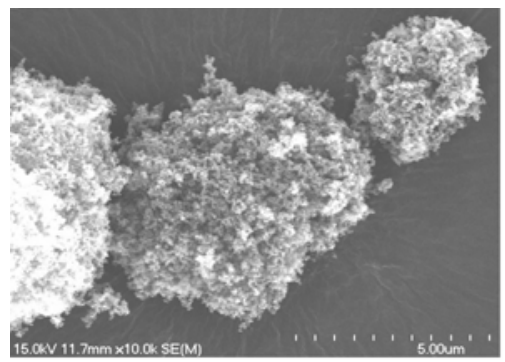

(a)

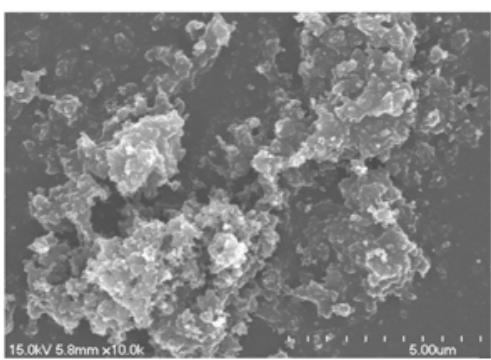

(b)

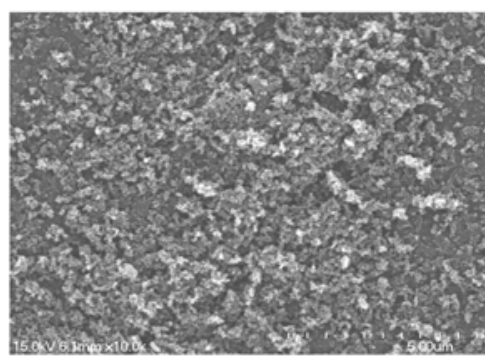

(c)

Fig. 1. SEM images of (a) raw N330-f, (b) N330-f-B and (c) N330-f-A $(\times 10,000)$. 


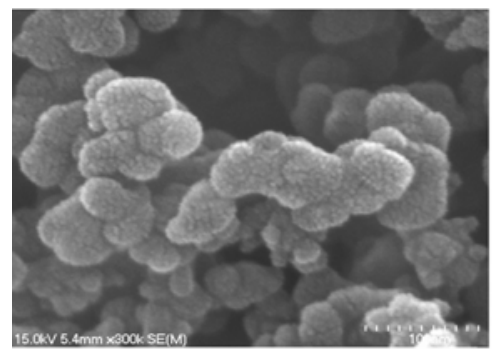

(a)

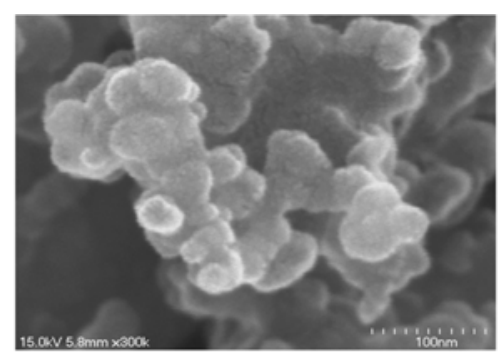

(b)

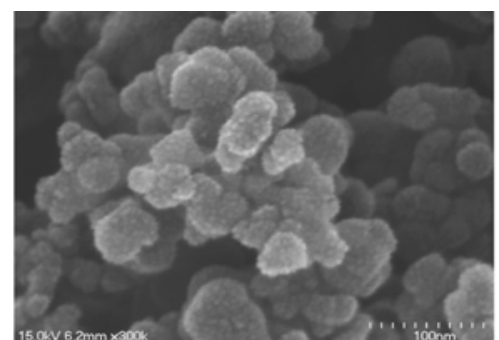

(c)

Fig. 2. SEM images of (a) raw N330-f, (b) N330-f-B and (c) N330-f-A (×300,000).

the heat treatment.

The SEM images of carbon blacks after chemical modification are shown in Fig. 1 and Fig. 2. In Fig. 1, carbon black clusters were broken after modification which might be caused by stirring carbon blacks in the chemical solutions during surface modification process and this could explain the increase of specific surface area after treatment. Fig. 2 shows that the carbon particles adhered to each other after base treatment, whereas it was easily to see carbon black particles after acid treatment which might be caused by the breaking of carbon aggregates. According to Park et al. [8], when the process temperature is below $800^{\circ} \mathrm{C}$, the surface functional groups of carbon black are less stable and develop acidic groups; when the process temperature is higher than $800^{\circ} \mathrm{C}$, the surface functional groups are more stable and favor formation of basic oxides, such as pyrone and chromene groups. Carbon black production processes were usually carried out with a temperature higher than $800^{\circ} \mathrm{C}$. Therefore, it is considered that basic surface functional groups might react with acid solution and this reaction leaded to the severing of acid treated blacks (N330-f-A) particles from carbon aggregates as shown in Fig. 2. Therefore, base treated blacks (N330-f-B) showed a higher specific surface area than raw blacks (N330-f) but lower specific surface area than N330-f-A.

\subsection{Mechanical properties of carbon black/rubber composites}

It is well known that the mechanical properties of carbon black filled rubber composites depend strongly on the degree of adhesion between the carbon blacks and the rubber matrixes. With the same loading, N330-f-H filled SBR rubber composites gave better tensile strength and elongation at break value than raw N330-f filled ones as shown in Fig. 3. With higher specific surface area and total pore volume, N330-f-H certainly had better reinforcement ability and enabled a better adhesion between the carbon blacks surface and SBR which might be caused by the higher probability of SBR occluded into carbon fillers.

Mechanical properties of SBR rubber filled by raw N330f, N330-f-B and N330-f-A are reported in Fig. 4. The composites filled by carbon blacks after chemical surface modification also showed higher tensile strength at the same loading but similar elongation values as compared with the composites filled by raw black. The higher tensile strength could be explained by the same reason with N330-f-H. It was interesting that N330-f-A which had a much higher specific surface area than N330-f-B showed a comparably

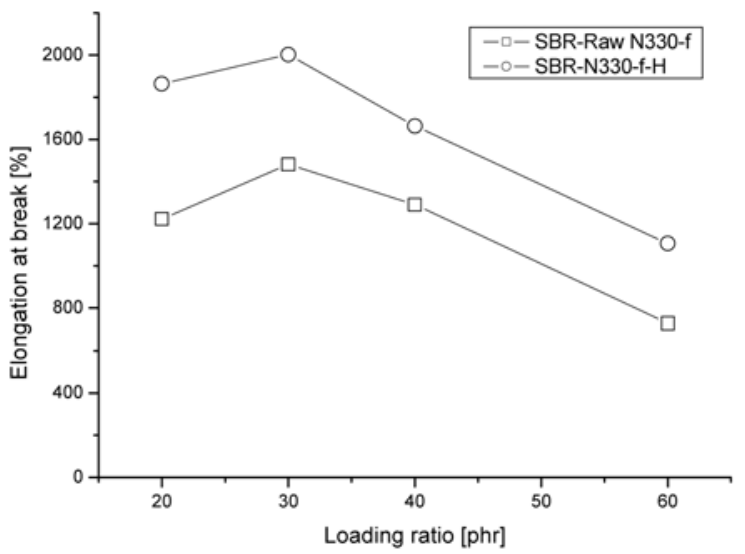

(b) elongation

Fig. 3. Tensile strength and elongation versus loading ratio for composites filled by raw N330-f and N330-f-H. 


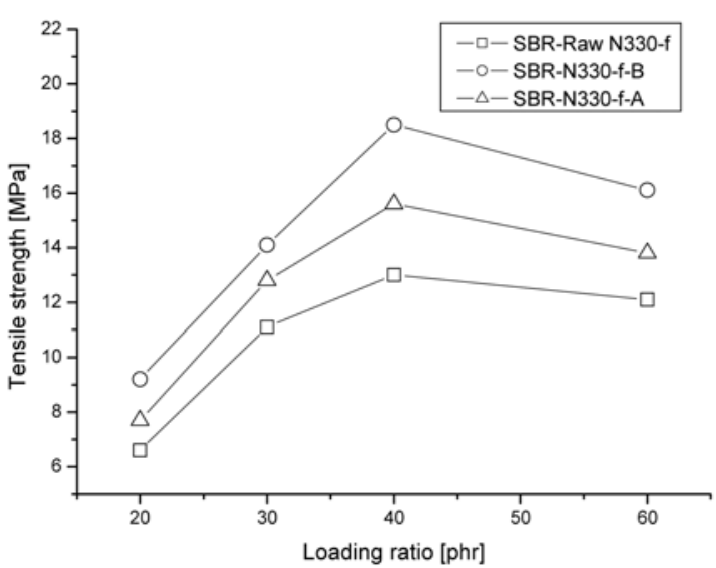

(a) tensile strength

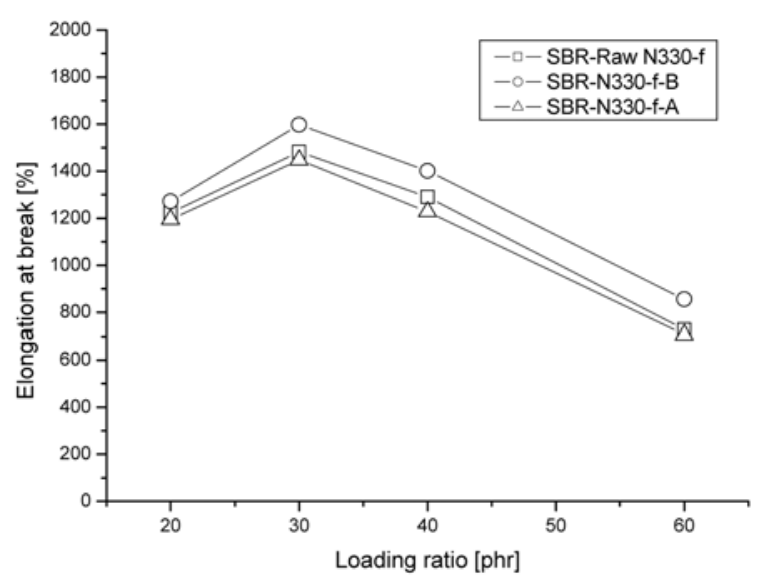

(b) elongation

Fig. 4. Tensile strength and elongation versus loading ratio for composites filed by raw N330-f, N330-f-B and N330-f-A.

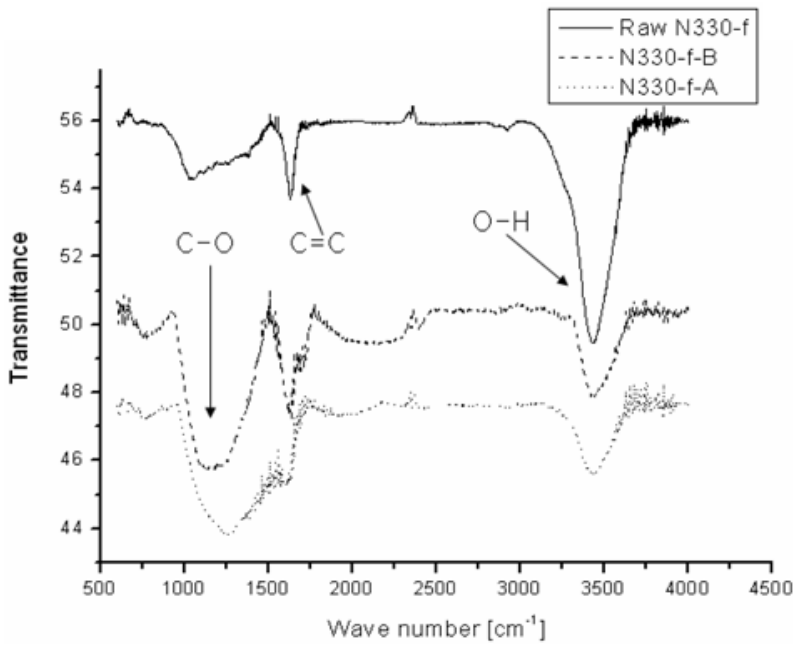

Fig. 5. FT-IR graphs of N330-f black before and after chemical modification.

lower tensile value. This indicated that the surface chemical properties would play an important role in the reinforcing action of carbon blacks. Also it was supposed that base treat- ment might lead to a formation of functional groups which were in favor of inducing strong intermolecular interaction between carbon surface functional groups and surface groups of SBR. The FT-IR result of N330-f black before and after chemical modification was presented in Fig. 5. It was seen clearly that after modification the surface functional groups were changed.

The increase in loading ratio causes a closer distance between aggregates in the in rubber system and a better fillerfiller interaction. At the same time the probability for the formation of a filler network increases [11]. So the tensile strength increased with the raise of carbon black fillers up to a certain point.

SEM images of N330-f-H black/SBR composites with loading ratio at $20 \mathrm{phr}$ and $60 \mathrm{phr}$ are reported in Fig. 6. The cross fraction of composite with loading ratio $20 \mathrm{phr}$ showed a smoother surface than that with higher loading $60 \mathrm{phr}$. The quality of almost every carbon black containing system was highly dependent on the degree of dispersion the carbon black achieved throughout the matrix. With increasing loading, carbon black aggregates might reagglomerate with each other during the process of vulcanization and cause restric-

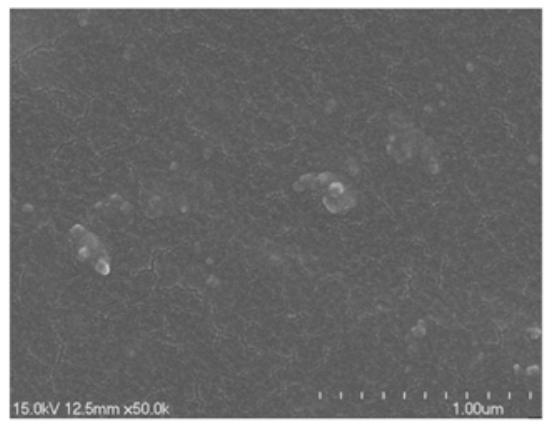

(a)

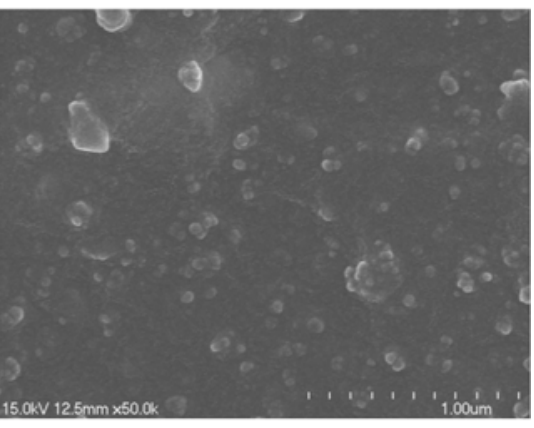

(b)

Fig. 6. SEM images of N330-f-H black/SBR composites with loading ratio at (a) $20 \mathrm{phr}$ and (b) $60 \mathrm{phr}(\times 50,000)$. 


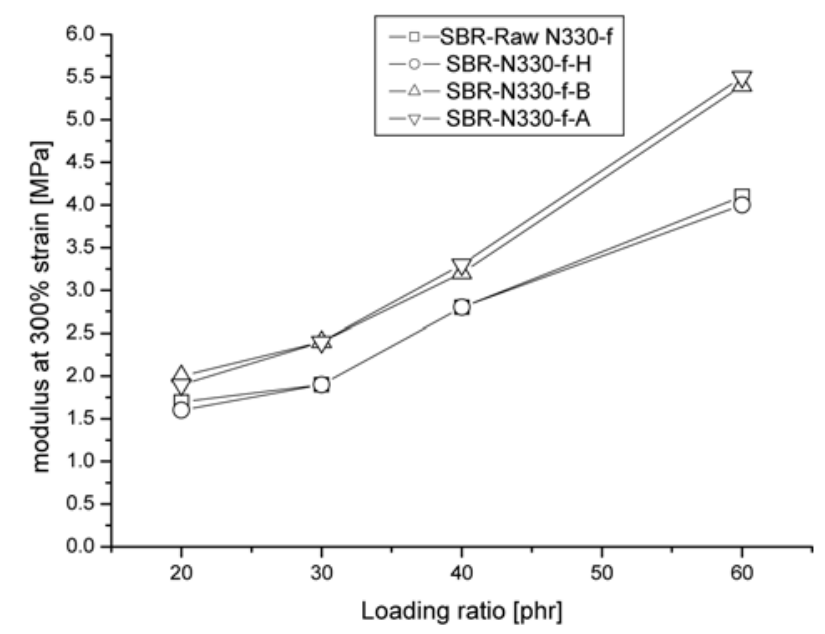

Fig. 7. Modulus at $300 \%$ strain versus loading ratio of various carbon blacks.

tions concerning the ability to wet effectively the carbon black aggregates with polymer [11]. As a result, carbon blacks could not uniformly distribute in SBR rubber. This could cause flaws in the in rubber system and simply leaded to a decrease in tensile strength and elongation at the higher filler loadings as shown in Fig. 3 and 4.

For carbon blacks of similar fineness (particle size distribution), higher structure (more irregular shapes) results in increased stiffness (modulus). Heat treatment was known to change surface properties without altering the particle size and structure to any important degree [11]. So N330-f-H filled composites showed similar modulus value with composites filled by raw $\mathrm{N} 330$-f at the same loading ratio. It was clearly seen from SEM images that N330-f-B and N330-f-A gave more irregular shapes, which might lead to the higher modulus values at the same loading.

With the increase in loading ratio, modulus at 300\% strain increased for all the composites as shown in Fig. 7. The further loaded carbon black could stiffen rubber by replacing the polymer with rigid, nondeformable particles. At the same time, the polymer occluded by aggregates which worked as a part of carbon blacks increased with higher loading and this could also increase rubber stiffness or modulus. Therefore, modulus always increased with increasing carbon black loading.

\section{Conclusions}

In this work, the mechanical properties of rubber composites filled by carbon blacks before and after the surface modifications with heat, acid, and base were investigated. The experimental results showed that the specific surface area of carbon blacks increased after the surface modifications but there was no obvious change in resistivity.

The composites filled by heat treated blacks showed higher tensile strength and elongation than those filled by raw blacks at the same loading ratio. The base and acid treated carbon blacks filled composites also showed a higher tensile strength, but similar elongation values with those filled by raw blacks.

The base treated carbon black showed comparatively low specific surface area and higher tensile strength value than acid treated blacks. This was supposed to be caused by changes on functional groups after the surface modification and further those surface functional groups affected the reinforcement of rubbers to a certain degree.

With the increase of loading ratio, both tensile strength and elongation increased for all the composites, and appeared a maximum value at $30-40 \mathrm{phr}$, whereas modulus at $300 \%$ strain remained increasing up to $60 \mathrm{phr}$ of loading.

\section{Acknowledgement}

This study was supported by "National R\&D Organization for Hydrogen \& Fuel Cell" and "Ministry of Commerce, Industry and Energy".

\section{References}

[1] Leblanc, J. L. Prog. Polym. Sci. 2002, 27, 627.

[2] Park, S. J.; Cho, K. S.; Ryu, S. K. Carbon 2003, 41, 1437.

[3] Horita, K.; Nishibori, Y.; Ohshima, T. Carbon 1996, 34, 217.

[4] Shanmugharaj, A. M.; Sabharwal, S.; Majali, A. B.; Tikku, V. K.; Bhowmick, A. K. J. Mater. Sci. 2002, 37, 2781.

[5] Takada, T.; Nakahara, M.; Kumagai, H.; Sanada, Y. Carbon 1996, 34, 1087.

[6] Park, S. J.; Seo, M. K.; Nah, C. J. Coll. Int. Sci. 2005, 291, 229.

[7] Taylor, R. "Introduction to Carbon Technologies", ed. Marsh, H.; Heintz, E. A.; Rodríguez-Reinoso, F. University of Alicante, Spain, 1993, 185.

[8] Park, S. J.; Kim, J. S. J. Coll. Int. Sci. 2000, 232, 311.

[9] Song, M. S.; Zhang, H. Z. Polymer Bulletin 1987, 17, 63.

[10] Edwards, D. C. J. Mater. Sci. 1990, 25, 4175.

[11] Frohlich, J.; Niedermeier, W.; Luginsland, H.-D. Composites: Part A 2005, 36, 449. 